\title{
Intermedial Experience and Ekphrasis in Wordsworth's
}

\author{
"Slumber"
}

Jarkko Toikkanen

University of Tampere

A slumber did my spirit seal;

I had no human fears:

She seemed a thing that could not feel

The touch of earthly years.

No motion has she now, no force;

She neither hears nor sees;

Rolled round in earth's diurnal course,

With rocks, and stones, and trees. ${ }^{1}$

There has been no shortage of debate on William Wordsworth's “A slumber did my spirit seal" (1800) in the last century. From the biographically oriented readings of E. D. Hirsch (1960) and Richard E. Matlak (1978) to the psychoanalytically charged views of Geoffrey Hartman (1964) and J. Hillis Miller (1979) and the

\footnotetext{
* This article was completed in working for The Academy of Finland project (285144) "The Literary in Life: Exploring the Boundaries between Literature and the Everyday," and the idea for it was first formulated at the IAPL (International Association for Philosophy and Literature) 2008 conference in Melbourne, Australia.
} 
pragmatically steered interpretation of Robert B. Meyers (1980), as well as linguistic experiments such as Steven Knapp and Walter Benn Michaels's (1982) imaginary play on the poem, along with Peggy Kamuf's (1986) and Marc Redfield's (2011) critical responses to their experiment, and a wide variety of thematic readings, such as Pieter Vermeulen's (2009) understanding of community inspired by the philosophy of Jean-Luc Nancy, "Slumber" has undergone many transformations. $^{2}$

My contribution to the discussion will take the form of dividing some of the most influential comments of the poem into two interpretive positions, shock readings and non-shock readings, and of responding to "Slumber" through the concept of intermedial experience and the rhetorical device of ekphrasis. Authorities in the shock position include F. W. Bateson (1950), Cleanth Brooks (1951), Brian G. Caraher (1991), and Richard Adelman (2011), and, in the nonshock one, Hugh Sykes Davies (1965), Paul de Man (1983[1969]), and Charles Rzepka (2008). The two interpretive positions are relevant to a number of issues for which "Slumber" has frequently been analyzed in debates on Wordsworthian Romanticism, as well as to the discussion of narrative selves involved in the intermedial experience of poetry.

My use and understanding of intermedial experience and ekphrasis continue those of my 2013 monograph The Intermedial Experience of Horror, as well more recent work on the concept of experience in both literary and media studies (2017a, 2017b; Toikkanen and Virtanen 2018). The current field of intermediality research is wildly spread out in multiple directions, theoretical and practical (see Jensen; Rippl; Wolf; Rajewsky), and here my aim is neither to map the entire field nor to propose a new paradigm but to add to the options at the researcher's disposal. 
My focus is on intermedial experience rather than on intermediality understood as, for instance, configurations or transformations that take place between two forms of art or media formats such as literature, painting, and video games. For the purpose, the concept of medium must be revised to refer, in the first place, to the five senses on which awareness and perception are classically founded — sight, hearing, touch, smell, and taste (see Hill; Classen). ${ }^{3}$ When intermedial phenomena are grasped as rooted in this basic level, their experiential quality comes into full view and enables, within intermediality research, the study of experiences (and descriptions of experiences) that may be either real or imagined. What do readers see in their mind on reading literature, how do they experience the seeing, and how do they respond to the experiences described in the literature? The presenting medium of word turns into the visual medium and, in the process, affects the reader's intermedial experience in a medium-specific manner. Indeed, reading engages the other senses too, and "Slumber" could be analyzed, for instance, in terms of its haptic imagery ("The touch of earthly years") or its kinesthetic imagery ("Rolled round in earth's diurnal course"). However, the visual is accented here because an experience of seeing between dream and reality arguably preoccupies the poem's narrative self and spreads out.

The way in which the words of "Slumber" can turn into visual images in the reader's mind may emerge from the poem's rhetorical design. To account for it, I shall focus on the device of ekphrasis. Ekphrasis has traditionally been familiar to scholars as poetry about paintings and, since the 1990s, first as the verbal representation of a visual representation (see Mitchell; Heffernan) and, second, as a figurative transposition shifting a representational element between any two media (see Clüver; Yacobi). As I have argued elsewhere, in contrast to other rhetorical 
devices such as hypotyposis whose function it is to make readers "see words," or to visualize the verbal, ekphrasis is charged with an interpretive demand. ${ }^{4}$ What is the meaning of the visual image produced by the words read, and how does the reader (or possibly the narrator of a literary text) go on to make sense of the image that is there to be not just seen but also interpreted?

This article calls for a kind of visual reading that will not let the intermedial experience of poetry be reduced to an interpretive position. For even when such a position is not a fixed one, when it is sensitive to change from one reading to the next, each single interpretation consists of a narrative appropriation of the text by the reader. What does "Slumber" mean? Who is telling and/or writing the poem and how? What does the reader make of it? Who is the "I" at any point? Inevitable as such questions are, with each answer there always remains an excess of experience, something that is not part of the interpretation and cannot be exhausted by offering another. Becoming involved with the excess and reflecting on it will provide insight into how intermedial experience is constituted. In the readings of "Slumber," it has consistently been the empty space between the poem's two stanzas that has appeared to generate such excess.

Images that readers have seen in reading the poem, the narrative they have used to describe them in their own words, as well as the effect of the empty space on their responses, point to an intermedial experience and to the kind of significance one tends to assign to the poem's visual images. The images represent something - but what? Which narrative self is the source of their significance: the reader, the poetic I, or Wordsworth himself? What does the reading come to in terms of the selves involved? I argue that interpretive positions such as the "shock" and "non-shock" readings of "Slumber" can be viewed as ekphrases in which the 
reader verbally describes the images of the poem with the consequence of narrative appropriation. In taking sides, in a manner reminiscent of Stanley Fish's interpretive communities, the reading self reduces experience to an interpretive position, and so closes off the reading process subjectively into a private sphere that may or may not have public clout in the rhetorical contest between opposing sides. Studying the device of ekphrasis shows how reading as intermedial experience affected by empty space in "Slumber" both maintains and disrupts this sense of subjective closure.

\section{"Shock" and "Non-Shock" Readings}

As noted, readings of "Slumber" have frequently found the empty space between the poem's two stanzas highly important - in terms of meaning as well as textual detail. What is the relationship between the visual imagery in the first stanza (dreaming about a "thing") and the visual imagery in the second stanza (observing "rocks, and stones, and trees")? The "shock" readings (which do not necessarily agree with one another) can be identified through an emphasis on the gap as a transition from one experience to another between the two stanzas, whereas the "non-shock" readings (which may find themselves in agreement with some of the "shockreading" interpretations) regard the poem as an ongoing state of the mind that, the gap notwithstanding, conveys an uninterrupted experience.

\section{"Shock"}

Bateson's and Brooks's famous "shock" readings of the early 1950s, as accounted for by Hirsch, differ in their interpretations of the gap between the two stanzas. Whereas Bateson sees the poem's ultimately “pantheistic magnificence,” Brooks feels the "lover's agonized shock" at the "most powerful and horrible image" his 
sight is confronted with at the end (Hirsch 471-72). Brooks explicitly affirms that the transition between the two stanzas creates a "shock," but Bateson's jubilant reading also emphasizes the gap as a transition from one experience to another something important occurs in that empty space, one that shocks and transforms the intermedial experience. For Bateson, the transformation finally results in a positive reconciliation; for Brooks, the dream ends in agony and horror for the masculine poetic I. $^{5}$

The most extended case in support of the "shock" reading of "Slumber" must be Brian Caraher's book-length study. His pragmatic approach to reading literature is one that, aware of its own activity, seeks "a closure to our experience when it achieves a distinct and self-sufficient character" (23). Caraher continues: "The closure is not of necessity always the end or result that one desires, nor is the course of an experience always pleasing" (23). Caraher, in other words, agrees with the above point on the similarity of Bateson's and Brooks's positions because both of them bring about closure, even if with different affective effects. He then proceeds to stake his own claim about Wordsworth as "a Romantic fantast at deadly play" (62) who, in "Slumber," shocks our attempts to place the poem's images in a definitive interpretive context. For Caraher, in the spirit of Deweyan pragmatics, the reader does well to step back, recall their contextual conditions in interpreting any literary text, and adjust to the shock. This is because "[c]ultures inscribe habitual selves within their structured fabrics" (236), and so it is the culture the reader inhabits that closes off the way in which a text can be experienced. Narrative selves vary from one reading to the next and are shocked by a cultural system that is put into place by those very selves seeking to recognize themselves in it. The poem becomes, in a manner of speaking, a reflection of the reader's life situation 
appropriated by its own cultural vagaries. As suggested by Bo Pettersson (), Caraher's pragmatics can end up placing too much emphasis on readers reading themselves.

The difference between Caraher's reading of "Slumber" and those of Bateson and Brooks is his acceptance of a textual detail originally pointed out by Hugh Sykes Davies. The "she" who first comes into view in line 3 may refer to "my spirit" in line 1 and not to the elusive "Lucy" after whom the five poems in the Lucy sequence have been named. ${ }^{6}$ In turn, one might ask, if "she" is not Lucy, do we need to think of the "I" as Wordsworth himself? While Keats would have said yes (as in his letter to Richard Woodhouse in October $1818^{7}$ ), the textual surface of "Slumber" makes no such demand, and allows the reader to overrule biographical or psychoanalytical readings. Caraher goes on to critique Davies's reading of the poem for "fail[ing] to take into account the surprise or shock that occurs in the second stanza of 'A Slumber' when the present-tense verbs alert a reader to a significant temporal displacement" (34). Yet it must be noted that, in disagreeing with Davies, Caraher actually draws a link between the "shock" and "non-shock" readings. In both camps, the critical finger invariably points at the juncture between the empty space separating the stanzas and the change in the poem's grammar and diction.

Richard Adelman has endorsed Caraher's "masterful treatment of the poem's syntax" to explain his own understanding of "Slumber," the gap included. For him, the poem's meaning is author-oriented as the playfully creative Romantic thought of Cowper and Coleridge — or "idle thought" (Adelman 101) — is redefined and transformed into something much more serious in Wordsworth: 
Where Cowper and Coleridge portrayed the possibility of redefinition in the image of one object [creative thought as "a single fire or the idea of a gale"], "A Slumber" considers redefinition by death. . . . Wordsworth's idle reverie passes beyond specific physical danger to categorically invoke death, and burial, as a physical reality. What was localized and therefore containable in Cowper and Coleridge, is rendered conceptual and universal by Wordsworth. (102)

Turning to this "realm of philosophical gravity" (103) in which "Slumber" comes to represent "an examination of the dangers of idle thought" (104) rather than a playful fancy, Adelman places himself squarely in the "shock" position with Brooks, Bateson, and Caraher. The difference in perspective lies in the severity and scope of the threat posed. Whereas Brooks and Bateson deal with private loss and gain and Caraher with reader pragmatics, Adelman interprets the poem by dissolving its significance into the public. He releases the intermedial experience of "Slumber" from readings bound to the fate of the Lucy figure and the poetic I, and from the dreams of individual readers in general, and raises it to philosophical shock death is the final state of idle thought for authors and readers alike. The near-cosmic terror of the second stanza overwhelms the personal distress of the first, enforced by the poem's empty space. Adelman's tone is certainly unsettling and adds further anxiety to most "shock" interpretations.

\section{"Non-Shock"}

In “To Be a Thing” Rzepka wonders why no critic has endorsed Davies's “carefully reasoned and supported argument" that there is no shock or transition from one 
experience to another between the two stanzas of "Slumber" (57). In 1965, Davies interpreted the poem "as expressing a distinctive, trancelike state of mind" that makes the poet's 'observing 'spirit' and what it observes a single, transcendental unity” (Rzepka 56). However, says Rzepka, Davies was left unsupported in this reading. The reason for this, as noted by Caraher above, was that Davies overlooked the "significant temporal displacement" that takes place in the poem (Caraher 34). Why is the first stanza written in the past tense and the second in the present? For the "shock" critics, the poem obviously describes two separate experiences; they attempt to read them together and reconcile them in one way or another, according to their respective interpretive schemes (whether reader pragmatics or authororiented philosophy). But how can a poem that contains such a gap be said to describe an ongoing state of the mind?

Rzepka's answer is the suggestion that the shift in tense may mark a broadening of perspective on the original event, a realization of its true meaning. While time has indeed passed, he argues, it does not follow that the initial experience will have changed into a different one through shock. Instead, the initial experience has been developing into a more mature version of itself. Rzepka is not arguing that interpreting "Slumber" as an ongoing state means that the two points in time marked by the shift in tense are simultaneous but that the present experience being described (recollecting the past in the first stanza, meditating on the present in the second stanza) contains them both. For him, as it occurs, the overall effect is not one of "shock" but "non-shock," and the intermedial experience afforded by the poem is reassuring rather than desperate. Rzepka's idea is based on the Heideggerian terms of "thing" and "gathering." In his vision of continuity, the "spirit" of "Slumber" is literally a thing gathered as the living material being of the 
human body instead of its death or Cartesian imprisonment in the flesh. This signals an organic unity growing in awareness that exceeds dualistic boundaries. ${ }^{8}$

Rzepka also touches on de Man's treatment of "Slumber," and at first it might appear that he is not siding with it. This is because de Man does not refute the Lucy reference and does not engage with Davies. ${ }^{9}$ However, one can argue that, as de Man understands Wordsworth as "one of the few poets who can write proleptically about their own death and speak, as it were, from beyond their own graves," in de Man's reading the pronoun "she" is "large enough to encompass Wordsworth as well” (de Man 225). In this poetry, according to de Man, the figure of the author imaginatively consists of all the deictic references made under its name, and so it does not matter (as Keats would have concurred) who apparently speaks because it is still Wordsworth's voice that reverberates throughout the intermedial experience of "Slumber." Consequently, as "the poem is written from the point of view of a unified self that fully recognizes a past condition as one of error and stands in a present that, however painful, sees things as they actually are" (ibid., 224), de Man's interpretive position interestingly resembles Rzepka's. It could be understood as one in which the shock of inevitable temporal progression matures into an uninterrupted experience of all-encompassing subjectivity. Wordsworth the poet, as the narrative self whose presence saturates everything he writes, resigns his own mortality to nature in order to see himself in all natural things, that is, in the "rocks, and stones, and trees" of "earth's diurnal course." For de Man and Rzepka alike, the poem describes an ongoing state of mind because its interpretation in this manner does not require the reconciliation of two separate experiences - there always is just the one experience. In transcending shock and 
the finality of death, as well as the poem's empty space, the two readers gain a sense of interpretive stability and subjective closure.

\section{Intermedial Experience and Ekphrasis}

I claimed in the beginning of this article that intermedial experience is not to be reduced to an interpretive position because with each interpretation - or narrative appropriation of the text by a reader — there always remains an excess of experience that is not part of any interpretation. What definition of experience can the reader then operate with, unless one is to admit defeat and regard excess as the unthinkable and unsayable "immediate" dimension of experience? Martin Jay has defined the concept of experience in the following way:

"Experience," we might say, is at the nodal point of the intersection between public language and private subjectivity, between expressible commonalities and the ineffability of the individual interior. [It is] something that has to be undergone or suffered rather than acquired vicariously. (Jay 2005: 6-7)

According to Jay, experience takes place where the public (social and cultural language) and the private (speechless selfhood) meet, and it cannot be sustained second-hand, or through someone else undergoing it. Moreover, because any experience involves both the public and the private to some degree, there can be no exclusively public or private experiences at all. Indeed, because the ideas of "public language" and "private subjectivity" are linguistic constructions, they do not exist as such in their own separate realms but only in the tension between them. When 
someone tells themselves "it is I who is having this experience," they confirm their subject position as distinct from other positions and close off the experience into a private sphere. In the case of reading a literary text, doing so gives rise to individual interpretations — of "my" reading against any other. For Caraher, this is the point of any pragmatic effort to read and, in taking sides, what follows from this reduction of experience is the public rhetorical contest of conflicting interpretive positions.

By contrast, I would argue that in the very act of thinking that "it is I who is having this experience" the reading self is no longer undergoing a private experience. In thinking about the experience, the private matter has already become a public abstraction assigned to an imaginary agency — that of the "I." The reading is linguistically confiscated by an expressible commonality speaking in its name from the inside. There is nothing that one can do to avoid this happening. Whether one reads to produce the most convincing interpretation possible, professional or non-professional, or whether one reads to enjoy the text in the solitude of one's innermost being, the linguistic confiscation has taken place. In this sense, academically theorizing about a text or experiencing it "raw," without speech or critical prejudice, do not inherently differ from each other: they go through the same cognitive mechanism.

What does my (possibly Hegelian) argument entail, in effect? If it is indeed true that the experiencing I is a mere placeholder for the experience being undergone, it follows that one cannot simply expect the involved self to explain, or refuse to explain, the experience. One must look at the means by which the intermedial experience specifically comes into being, that is, at the medium of the presentation. In the case of "Slumber," the presenting medium is word. In reading 
the poem, the word turns into the visual medium and, in the process, affects the reader's intermedial experience in a medium-specific manner. The imagined visual images waver in and out of the reach of the poem's different "I"s, through and across the gap — or, perhaps, the "nodal point" in Jay's terms — between the two stanzas. The experience that the reader undergoes simultaneously, as it were, with the experience described in "Slumber" is intermedial in nature. When the words vanish into the poem's empty space, the intermedial experience of reading the poem is disrupted and, once the words return in the second stanza, the reader must respond. How to verbalize this non-verbal excess? Was the poetic I transformed by the sudden disruption? Does the reading I even possess the authority to answer that question? The "shock" and "non-shock" readers of "Slumber" have endeavored to interpret the excess of their reading experiences to produce their own respective narratives.

The rhetorical device of ekphrasis can help to clarify this process. Word is the specific medium of the presentation of Wordsworth's poem, and, in most readings, its two key visual images have to do with dreaming about a "thing" (who or what is it — "she," spirit, or Lucy?) and observing the "rocks, and stones, and trees" of "earth's diurnal course." If the reader gleans the words of "Slumber" as describing either a transformative or a transcendental experience for the poetic I, based on figurative transposition, in reading the poem one re-enacts the experience, sights the "thing" and the "rocks, and stones, and trees," and interprets the visual images accordingly (“This is who 'she' is and what 'earth's diurnal course' means"). In other words, as a result of one's intermedial experience of poetry, one produces an ekphrasis that is conceived of as the public fruit of the reading I's private labor. The reading I has successfully represented in words what the poem's 
images represented for the poetic I, or, perhaps, Wordsworth himself. Then again, even if the reader deflected any life-changing experience, "shock" or "non-shock," for the poetic I beyond the textual surface of the poem, one was yet bound to produce an ekphrasis — the verbal representation of the reading I's experience of what the poem's images represented for us as the readers of "Slumber." In this case, the end result might be pragmatic, but the intermedial process and cognitive mechanism that have given rise to it and have led to the result would remain unchanged. There is a sense of interpretive stability and subjective closure in how the poem's meaning is perceived.

If the reading process usually tends to pan out in such a way, what particular insight can one gain through an analysis based on intermedial experience and ekphrasis in Wordsworth's "Slumber"? Reading the poem in this rhetorical fashion exposes the kind of significance readers have assigned to its key words turned into visual images; it also brings out the excess of intermedial experience that is not part of any interpretation. Ekphrasis is charged with an interpretive demand that is distinct from other rhetorical devices; it is geared toward the meaning of the visual image produced by the words read and, in turn, toward the matter of the narrative selves involved in the intermedial experience of poetry.

An ekphrastic diagnostic borrowed from W. J. T. Mitchell will further demonstrate the merit of the exercise. In Picture Theory, Mitchell identifies "three phases or moments of realization" that are related to one's fascination with imagined images (152). The first phase is "ekphrastic indifference," or the realization that images conjured up by words will never be real in the manner of visual images: "A verbal representation cannot represent — that is, make present — its object in the same way a visual representation can" (ibid.). The second phase is 
“ekphrastic hope," or the moment when "the impossibility of ekphrasis is overcome in imagination or metaphor" (ibid.). It is the magical instant when one suddenly imagines that art and poetry are endowed with the power to make unreal images come into being, more real than reality itself, on a transcendental plane beyond the realities of this world. ${ }^{10}$ The third phase is "ekphrastic fear." Here one encounters "the moment of resistance or counterdesire that occurs when we sense that the difference between the verbal and visual representation might collapse" (154). If the gap between the two media at odds with each other were ultimately bridged over, and the image became as one with the word, it might well turn out to be something one never wanted. In some Romantic cases, the consequences could be mild, such as spoiling the surprise or exhausting a mystery in the manner of Ann Radcliffe's The Mysteries of Udolpho (1794), which returns the reader to the phase of indifference. In other cases, such as Shelley's “Ozymandias” (1818), the mystery is suspended in timeless desolation, whereas in Keats's "Ode to a Nightingale" (1819), the desire to transcend mundane life brings about a last-minute jerk back into reality. Then again, the consequences could, at their worst, result in the kind of visionary insanity epitomized by the strange old sailor of Coleridge's The Rime of the Ancient Mariner (1798).

If one uses Mitchell's method to make sense of "Slumber" and considers some of the poem's previous readings from either camp, it could be argued that Caraher's pragmatic approach is well in line with the first phase, that of ekphrastic indifference. "Slumber" is simply a poem to be interpreted in the reader's context, contingent on changing cultural conditions, not on any meaning hidden deep in or between the verses. Then again, it can be confidently argued that even if many "shock" and "non-shock" readers of "Slumber" differ excessively in their takes on 
the empty space between the poem's two stanzas, they do so in the ekphrastic hope of uniting the poem's words with its images. Regardless of interpretive camp, this hope is particularly pronounced in Bateson with his celebration of nature's glory, and in Davies with his vision of transcendental oneness. It could also be claimed that although Brooks stresses the terrifying experience of the poetic I, his is still a hopeful reading of agonistic heroism, and it is not wrong to say that Rzepka, in his Heideggerian gathering of the poem as organic awareness, yields high hopes for its future.

The two readings in which I find analogies to ekphrastic fear are Adelman's and de Man's. Because Adelman interprets "Slumber" in a manner that tears it away from the individual reader, dissolving its significance into the public, the universal death implied by Wordsworth as understood by Adelman is frightening enough to make the reader want to look away from the poem, to separate the words from the images and reassert the gap. Of course, one could argue that Adelman's nihilistic reading of near-cosmic terror is, indeed, only the reverse of Davies's transcendental vision. However, the difference between them in terms of the three phases of ekphrasis is that whereas Adelman, unlike Davies, is recommending active philosophical caution, or skepticism. Davies seems to dive into the dreamy reverie of "Slumber" headlong.

Then again, although de Man seems to support the view that the poem conveys an uninterrupted experience of all-encompassing subjectivity — and also the idea that, in a deadly fashion, the author Wordsworth succeeds in what he sets out to do - the reader never enjoys the same privilege. It comes at too high a cost. Across the poem's empty space, the reader remains at a distance from all the figures involved, Wordsworth, the poetic I, the enigmatic "she." Whereas for de Man the 
author falls prey to his own imaginings, and writes from beyond death, the reader avoids such fate, remaining outside the poem. The reading I realizes that one is forever separate from the poetic I - that the words and images experienced by one figure will not match the words and images experienced by another figure, real or imagined. The desire for shared experience remains, however. If Wordsworth could have it, why could not I? Beyond the comfort of conflicting but stable interpretive positions afforded by other readers, the intermedial experience of this urge harasses the reader with excessive promises that go unfulfilled, while at the same time it disrupts the sense of subjective closure and maintains an ongoing loop of ekphrastic phases.

\section{Twisting the Image}

When intermedial experience resists reduction to an interpretive position, the process of reading is brought into focus, and the reader becomes involved with the excess of their reading experience and can note the means by which the intermedial experience of poetry comes into being. As I have argued, study of the workings of ekphrasis helps us to understand how reading as intermedial experience both maintains and disrupts the sense of subjective closure, the sense of "my" reading against any other, and how it may fare in the public rhetorical contest of conflicting interpretive positions. The matter of the narrative selves involved in the mediumspecific environment of Wordsworth's verbal art comes into focus.

Ekphrasis aside, Mark Jones has expressed a similar thought about the long catalogue of responses to the Lucy poems: 
$[\mathrm{H}]$ ow and why does [Wordsworth's] poetry create the complexities that seem to demand simplification? And how and why do critics repress this complexity — that is, not only in interpreting, but also in denying the extent to which the poetry demands interpreting in the first place? (97)

Jones claims that the theoretical frames within which the Lucy poems have been interpreted have operated from "predictable institutional categories" (98), foregoing and containing the peculiar intricacy of Wordsworth's work. As his own contribution, Jones stresses the "dialectical romantic symbol" as the key figure by which the reading could be done differently: "The romantic symbol may be a medium of knowledge, but it is not a pure medium; its core of being leaves an untranslatable remainder; it resists full and definitive appropriation" (102). This "untranslatable remainder" is not dissimilar to the excess of experience that I have discussed in this article, when poetic imagery as "a medium of knowledge" is equated with interpretation as a narrative appropriation of the text. Jones does not explore the theory of the Romantic symbol extensively, but it is surely an avenue that warrants inquiry — as Murray Krieger has demonstrated in Ekphrasis: The Illusion of the Natural Sign. I conclude by revisiting two of Krieger's key ideas, with the twist to intermedial experience.

For Krieger, "to look into ekphrasis is to look into illusionary representation of the unrepresentable" (xv). The premise fits Jones's understanding of the Romantic symbol. As Wordsworth's Lucy is "properly reducible neither to material human being nor to idea," she remains "essentially unknowable" (102) and, in effect, unrepresentable except through ekphrastic illusion, as Krieger might say. The gap appears unbridgeable. And although ekphrasis gives no direct access to 
knowledge or immediate nature, Krieger notes that in reading there is no way around it:

we must stay with the poem and with the imagined object it inspires in us, since its supposed object of imitation is only that imagined object. It is our unattainable dream of a total verbal form, a tangible verbal space. We may see it as the poem's miracle, and that seeing is our mirage. (xvii)

Krieger, in other words, has "ekphrastic hope" - for him, too, "the impossibility of ekphrasis is overcome in imagination or metaphor" (Mitchell 152). The reader's intermedial experience of the poem's "miracle" may be tempered with the indifferent knowledge that it is only a "mirage," but the fact does not diminish the power of the illusion. Because even if the gap appeared unbridgeable, it would not stop the reader from imagining otherwise. The "shock" and "non-shock" readings of "Slumber," with their varying views on the public or private consequences of the poem's meaning, are evidence for this.

Poetic imagery such as the elusive Lucy figure — as memorable a Romantic symbol as ever was — points to the source of Krieger's "unattainable dream." Yet his dream fails to recognize that whatever appears as Lucy might not be Lucy at all. The identification is soothing and empowering but textually ungrounded. One may discount the Lucy theory in the context of "Slumber," as many readers from Davies onwards have done. Yet what does remain if the reader lets go of the Lucy dream? What happens to the intermedial experience of poetry if the reader has no narrative self to assume the main role in "Slumber"? 
What remains, in my reading, is the harsh miracle of Romantic introspection pushed too far, into the empty space between the two stanzas, where the reading I dare not follow the poetic I. Ekphrastic fear affects the intermedial experience of sheer excess that is Krieger's illusion. Both the hope of unity and wisdom and the anxiety of universal death are only promised in the form of their repeated disruption. The poem's visual imagery is twisted not by indifferent knowledge ("these are only images in a poem"), but by the reader's failure ("I do not know why I keep seeing the images") to control it. Just as the "rocks, and stones, and trees" roll round in "earth's diurnal course," what is read keeps turning into what is seen, the seen back into the read — and there is nothing shocking about that. The ongoing shock is the reader's intermedial experience of being unable to maintain a sense of interpretive stability and subjective closure except through comforting illusion or the premonition of death.

\section{Works Cited}

Adelman, Richard. 2011. "Idle Thought in Wordsworth's Lucy Cycle." Romanticism 17/1: 94-105.

Baker, John, Jr. 1997. “Grammar and Rhetoric in Wordsworth's 'A slumber did my spirit seal': Heidegger, de Man, Deconstruction.” Studies in Romanticism 36/1: 103-23.

Bateson, F. W. 1950. English Poetry: A Critical Introduction. London: Longmans. Brooks, Cleanth. 1951. "Irony as a Principle of Structure.” In Literary Opinion in America, $2^{\text {nd }}$ edition, ed. M. D. Zabel. New York: Harper, pp. 729-41.

Caraher, Brian G. 1991. Wordsworth's "Slumber" and the Problematics of Reading. University Park, PA: Pennsylvania State University Press. 
Classen, Constance. 1993. Worlds of Sense: Exploring the Senses in History and Across Cultures. London: Routledge.

Clüver, Claus. 1997. "Ekphrasis Reconsidered: On Verbal Representations of NonVerbal Texts." In Interart Poetics: Essays on the Interrelations of the Arts and Media, ed. Ulla Britta Lagerroth, Hans Lund, and Erik Hedling. Amsterdam: Rodopi, pp. 19-33.

Davies, Hugh Sykes. 1965. "Another New Poem by Wordsworth.” Essays in Criticism 15/2: 135-61.

Edelman, Lee. 2016. "Brief Encounter: De Man on Wordsworth, or The Irony of 'The Rhetoric of Temporality." Romantic Circles vol. "Minimal Romanticism,” eds. David L. Clark and Jacques Khalip. https://www.rc.umd.edu/praxis/brevity/praxis.2016.brevity.edelman.html (September 18, 2018).

Ferguson, Frances C. 1973. “The Lucy Poems: Wordsworth's Quest for a Poetic Object." ELH 40/4: 535-48.

Fish, Stanley. 1980. Is There a Text in This Class? The Authority of Interpretive Communities. Cambridge, MA: Harvard University Press.

Greenberg, Clement. 1940. “Towards a Newer Laocoön.” Partisan Review 7: 296 310. https://west.slcschools.org/academics/visualarts/documents/Laocoon.pdf (September 18, 2018).

Hartman, Geoffrey. 1964. Wordsworth's Poetry 1787-1814. Cambridge, MA: Harvard University Press.

Heffernan, James A. W. 1993. Museum of Words: The Poetics of Ekphrasis from Homer to Ashbery. Chicago: The University of Chicago Press. 
Hill, Annette. 2011. "Audiences in the Round: Multi-method Research in Factual and Reality Television.” In A Handbook of Media and Communication Research: Qualitative and Quantitative Methodologies, $2^{\text {nd }}$ edition, ed. Klaus Bruhn Jensen. Abingdon: Routledge, pp. 302-17.

Hirsch, E. D., Jr. 1960. “Objective Interpretation.” PMLA 75/4: 463-79.

Jay, Martin. 2005. Songs of Experience: Modern American and European Variations on a Universal Theme. Berkeley: The University of California Press.

Jensen, Klaus Bruhn. 2016. “Intermediality.” In The International Encyclopedia of Communication Theory and Philosophy, ed. Klaus Bruhn Jensen and Robert T. Craig with Jefferson D. Pooley and Eric W. Rothenbuhler. Chichester: Wiley-Blackwell. http://onlinelibrary.wiley.com/doi/10.1002/9781118766804.wbiect170/full (September 18, 2018).

Jones, Mark. 1993. "On Knowing the 'Lucy Poems': Criticism as Containment.” ANQ: A Quarterly Journal of Short Articles, Notes, and Reviews 6/2-3: 96105.

Kamuf, Peggy. 1986. "Floating Authorship. Against Theory: Literary Studies and the New Pragmatism by W. J. T. Mitchell.” diacritics 16/4: 2-13.

Keats, John. 1818. “To Richard Woodhouse (Hampstead, October 27, 1818).” Poems by John Keats. http://keats-poems.com/to-richard-woodhousehampstead-october-27-1818 (September 18, 2018).

Knapp, Steven, and Walter Benn Michaels. 1982. “Against Theory.” Critical Inquiry 8/4: 723-42. 
Krieger, Murray. 1992. Ekphrasis: The Illusion of the Natural Sign. Baltimore: The Johns Hopkins University Press.

Man, Paul de. 1983 [1969]. "The Rhetoric of Temporality.” Blindness and Insight: Essays in the Rhetoric of Contemporary Criticism, $2^{\text {nd }}$ edition. London: Routledge, pp. 187-228.

Matlak, Richard E. 1978. “Wordsworth's Lucy Poems in Psychobiographical Context." PMLA 93/1: 46-65.

Meyers, Robert B. 1980. "Pragmatic Interpretation.” boundary 2: 115-40.

Miller, J. Hillis. 1979. “On Edge: The Crossways of Contemporary Criticism.” Bulletin of the American Academy of Arts and Sciences 32/4: 13-32.

Mitchell, W. J. T. 1994. Picture Theory. Chicago: The University of Chicago Press. Pettersson, Bo. 2002. "What Interpretive Divergence Can Teach Literary Semantics: Reconsidering Wordsworth's 'A slumber did my spirit seal.'” NJES - Nordic Journal of English Studies 1/2: 199-214.

Rajewsky, Irina O. 2005. "Intermediality, Intertextuality, and Remediation: A Literary Perspective on Intermediality." Intermédialités 6: 43-64.

Rautajoki, Hanna, Jarkko Toikkanen, and Pirkko Raudaskoski. (forthcoming). "Embodied Ekphrasis of Experience: Bodily Rhetoric in Mediating Affect in Interaction." Semiotica.

Redfield, Marc. 2011. "Romantic Poetry and Literary Theory: The Case of "A slumber did my spirit seal."” In A Companion to Romantic Poetry, ed. Charles Mahoney. Chichester: Wiley-Blackwell, pp. 467-82.

Rippl, Gabriele, ed. 2015. Handbook of Intermediality: Literature - Image Sound - Music. Berlin: de Gruyter. 
Robinson, Peter. 2018. The Sound Sense of Poetry. Cambridge: Cambridge University Press.

Rzepka, Charles. 2008. “To Be a Thing: Wordsworth’s ‘A slumber did my spirit seal' and the Paradox of Corporealization." Wordsworth Circle 39: 56-61.

Toikkanen, Jarkko. 2008. The Break of Paul de Man. Acta Universitatis

Tamperensis 1337. Tampere: Tampere University Press.

http://urn.fi/urn:isbn:978-951-44-7416-3 (September 18, 2018).

2013. The Intermedial Experience of Horror: Suspended Failures.

Basingstoke: Palgrave Macmillan.

----------. 2017a. “Auditory images in Edgar Allan Poe's 'The Tell-Tale Heart.”,

The Edgar Allan Poe Review 18/1: 39-53.

2017b. "Välineen käsite ja välinemääräisyys 2010-luvulla." Special issue

Totuus, valhe, media \& viestintä. Media \& viestintä 40/3-4: 69-76.

https://journal.fi/mediaviestinta/issue/view/4734 (September 18, 2018).

Toikkanen, Jarkko and Ira A. Virtanen, eds. 2018. Kokemuksen tutkimus VI:

Kokemuksen käsite ja käyttö. Rovaniemi: Lapland University Press.

Vermeulen, Pieter. 2009. “Community and Literary Experience in (between)

Benedict Anderson and Jean-Luc Nancy.” Mosaic: An Interdisciplinary

Critical Journal 42/4: 95-111.

Wolf, Werner. 2011. “(Inter)mediality and the Study of Literature.” CLCWeb:

Comparative Literature and Culture 13/3.

http://docs.lib.purdue.edu/clcweb/vol13/iss3/2 (September 18, 2018).

Wordsworth, William. 2012 [1800]. “A slumber did my spirit seal.” In The Norton

Anthology of English Literature, $9^{\text {th }}$ edition, gen. ed. Stephen Greenblatt, 
eds. Deidre Shauna Lynch and Jack Stillinger. New York and London: W.

W. Norton \& Company.

Yacobi, Tamar. 1997. "Verbal Frames and Ekphrastic Figuration.” In Interart

Poetics: Essays on the Interrelations of the Arts and Media, ed. Ulla Britta

Lagerroth, Hans Lund, and Erik Hedling. Amsterdam: Rodopi, pp. 35-46.

${ }^{1}$ The punctuation and spelling of Wordsworth's poem follow the format printed (307) in The Norton Anthology of English Literature, $9^{\text {th }}$ edition. The original version lacked the semicolons and the commas in the last line, contracted "seemed" and "Rolled" to "seem'd" and "Roll'd", had a comma at the end of the first line, as well as an exclamation mark at the end of the last line. Peter Robinson (2018) has noted that the changes to the last line in particular "may be understood as attempts by the orally composing textual poet to cue, for readers, the unusual significance to be intuited by slowing down the delivery of that final line's sound sense" (71).

${ }^{2}$ In Hirsch, see sections II (“Determinateness of Textual Meaning”) and III ("Verification") in particular. Matlak's whole essay is useful for the psychobiographical view, but see 55-57 more specifically on "Slumber". In Hartman, see chapter on Lyrical Ballads. Miller's article focuses on “Slumber" from page 20 onward, and Meyers's from page 119. In the famous Knapp and Michaels piece, see the Hirsch-critical section "Meaning and Intention". Kamuf's and Redfield's articles should be read from start to finish, Vermeulen from page 107 onward.

${ }^{3}$ I have been developing a three-tier model of mediality in which the five basic sensory means are indeed found on the first level. Different ways of presenting sensory perceptions (that may be either simple, such as speech and writing, or complex, including literature, painting, and video games) are located on the second level, and conceptual abstractions of such ways of presenting (multimedia, new media, mass media) on the third level. The model is a work in progress, updating the Modernist concept of medium-specificity as proposed by Clement Greenberg in 1940 (see Toikkanen 2017b). 
${ }^{4}$ See Toikkanen 2013 for a detailed account of this conceptual history and analytical distinction. For case studies on the method in action, see Toikkanen 2017a on reading auditory images in Edgar Allan Poe, and Rautajoki, Toikkanen, and Raudaskoski (forthcoming) on embodied ekphrasis in non-literary materials.

${ }^{5}$ In assessing the plausibility of the readings in terms of the poem's "most probable context," Hirsch sides up with Bateson because his "method" of interpreting the author's intention seems more "fundamentally sound" than Brooks's (477).

${ }^{6}$ The five poems often included in the Lucy sequence, written between 1798 and 1801, are "Strange fits of passion have I known," "She dwelt among the untrodden ways," "I travelled among unknown men," "Three years she grew in sun and shower," and "A slumber did my spirit seal." It had not been, however, Wordsworth's idea to present them as a specific cycle of poems; it was rather the anthologists who have traditionally done so. This decision has had consequences for readers' trying to establish the identity of the enigmatic "she" figure who may not remain the same throughout the sequence, and for whom there may or may not exist a real-life analogue such as, for instance, William's sister Dorothy (see Ferguson).

${ }^{7}$ In the letter, Keats snarls at the poetic attitude he describes as "the Wordsworthian, or egotistical Sublime", and dubs himself "the chameleon poet" who has no "self" or "character" to boast about and is therefore able to waive his identity in the creation of art.

${ }^{8}$ Rzepka follows in the footsteps of John Baker (1997) to develop this interpretive position of "nonshock": "There is no other 'thing' within which it can be 'sealed' than its own body. The 'thing' that 'spirit' gathers in gathering herself as 'a thing' turns out to be the body 'rolled round in earth's diurnal course"” (Rzepka 60).

${ }^{9}$ Caraher turns the tables on de Man for this very omission: "However, de Man seems to blind himself to the insight offered in the temporal structure of his reading, the temporal interaction of the poem and of himself as reader. Indeed he does not see a way to reconcile the feminine pronouns of 
the poem to the identity of the speaker. In other words, he does not see a way to probe into and come to terms with the experienced confusion in the reference of "she"" (91). Lee Edelman has recently (2016) criticized de Man for privileging an allegorical reading of "Slumber" over an ironical one — de Man is said to “champion allegory's duration over irony's vanishing-point of brevity" — which makes it seem as if the poem's two stanzas were spoken by a coherent even if alienated voice. However, Edelman sets aside the fact that de Man here speaks of Wordsworth's poetry, not poetry in general whose supremely ironic nature de Man confirmed and cherished throughout his scholarly career (see Toikkanen 2008).

${ }^{10}$ Interestingly, the phase of ekphrastic hope is also when "ekphrasis ceases to be a special or exceptional moment in verbal or oral presentation and begins to seem paradigmatic of a fundamental tendency in all linguistic expression" (Mitchell 153). This observation predates Clüver's and Yacobi's expansion of the meaning of ekphrasis from that of a rhetorical device focused on what happens between the verbal and the visual to that of a device applicable all across the media. 